\title{
Haematological Changes in Patients with Lymphoid Malignancies on Chemotherapy in Benin City, Edo State, Nigeria
}

\author{
Emmanuel .C. Onuoha ${ }^{1 *} \quad$ Mabel .E. Ike $^{2} \quad$ Tracy .A. Diepreye $^{3} \quad$ Ezekiel. F.Hallie $^{4}$ \\ Vivian. A. Maduka ${ }^{1} \quad$ Nake. Nelson-Ebimie $^{1} \quad$ Jangfa. N. Nden $^{1}$ \\ 1. Medical Laboratory Unit, Medical Services, Federal University, Otuoke, Bayelsa State \\ 2. Department of Zoology, Faculty of Natural Sciences, University of Jos, Nigeria \\ 3.Pharmacy Unit, Medical Service Department, Federal University, Otuoke, Bayelsa State, Nigeria \\ 4. School of Pharmacy, University of Liberia, Monrovia, Liberia
}

\begin{abstract}
Chemotherapy continues to serve as the best option therapy in treating human malignancies that have undergone metastasis and cannot be managed solely by surgical removal or radiation. The aim of this study is to evaluate the clinical important of haematological parameters in the management of lymphoid malignancy patients on chemotherapy to ascertain the impact of such chemotherapy on them.. This study was carried out in one secondary and one tertiary health institution in Edo State. It was divided into three groups: lymphoid malignancy on chemotherapy, novel lymphoid malignancy and apparently healthy individuals as controls. Using aseptic precaution, $5 \mathrm{ml}$ of blood is collected into $\mathrm{K}_{2}$ EDTA container for full blood count analysis using KX-21NSysmex automated Haematology analyser 2004 model and data were analysed using student $t$ test. The comparison between novel lymphoid malignant patient and controls indicate $\mathrm{WBC}$, lymphocytes and platelet count increase significantly $(\mathrm{P}<0.05)$ while RBC, HGB, HCT decrease significantly $(\mathrm{P}<0.05)$ when compared with control. However, $\mathrm{MCV}, \mathrm{MCH}, \mathrm{MCHC}$, monocytes and granulocytes were not significant $(\mathrm{P}>0.05)$. The comparison between lymphoid malignant patient on chemotherapy and controls shows RBC, HGB, HCT decrease significantly when compared with control $(\mathrm{P}<0.05)$ while $\mathrm{WBC}$, lymphocytes, platelet, $\mathrm{MCV}, \mathrm{MCH}, \mathrm{MCHC}$, monocytes and granulocytes were not significant $(\mathrm{P}>0.05)$. When lymphoid malignant patient on chemotherapy and novel lymphoid malignant patient are compared, it shows RBC, HGB, HCT increase significantly when compared with novel lymphoid malignant patients $(\mathrm{P}<0.05)$ while $\mathrm{WBC}$ and $\mathrm{MCHC}$ decrease significantly $(\mathrm{P}<0.05)$. However, lymphocytes, platelet, $\mathrm{MCV}, \mathrm{MCH}$, monocytes and granulocytes were not significant $(\mathrm{P}>0.05)$. we can deduce that full blood count is highly clinically important for an effective management of lymphoid malignant patients on chemotherapy.
\end{abstract}

DOI: $10.7176 / \mathrm{JMPB} / 61-04$

Publication date: November $30^{\text {th }} 2019$

\section{Introduction}

The summation of different malignant conditions from bone marrow cells and the lymphatic system origin is called Lymphoid malignancies (1). Genetic alteration in the bone marrow cell and lymphoid tissue at the surface area are the causes of these clonal diseases (2). Lymphoid malignancies include the following: acute lymphoblastic leukaemia (ALL), Chronic Lymphocytic leukaemia (CLL), prolymphocytic leukaemia (PLL), hairy cell leukaemia (HCL) and lymphomas such as: Hodgkin Lymphoma (HL), Non-Hodgkin Lymphoma (NHL), myeloma, indolent lymphoma, aggressive lymphoma according to World Health Organisation (3).

Chemotherapy continue to serve as the best option therapy in treating human malignancies that have undergone metastasis and cannot be managed solely by surgical removal or radiation (4). There was slow advancement in haematological chemotherapy in the first lap of twentieth century but rapidly development at last lap of twentieth century by certain important findings which cause a great change in the field of haematological chemotherapy for many terminal diseases. These important findings were (a) many antimetabolite and cytotoxic drugs development. (b) Tremendous development in blood product and supportive therapy permitting more intensive use of cytotoxic drug alone or in combination (c) Set of rule being developed for preemptive antibiotic treatment in immuno suppressed patient before microbiology laboratory results were available (d) Monoclonal antibodies advancement for management of different malignant and non malignant conditions (e) Recombinant proteins and more comprehension of basic techniques of cell growth, division, differentiation, migration and cellular death (5).

A full blood count (FBC) is a blood test that gives detail information about the kinds and numbers of cells in the blood, especially red blood cells, white blood cells and platelets. It also helps in the diagnosis of other opportunistic diseases (6).

Therefore, the aim of this study is to evaluate the clinical important of haematological parameters in the management of lymphoid malignancy patients on chemotherapy to ascertain the impact of such chemotherapy on them. 


\section{Materials aand Methods}

\subsection{Study Area/Sample Size}

The study population composed the lymphoid malignant patients from 18 years and above. The total population of sixty (60) subjects was divided into three groups as follows:

Group1: Twenty (20) lymphoid malignant patients on chemotherapy.

Group2: Twenty (20) novel lymphoid malignant patients. ,

Group3: Twenty (20) controls (those without lymphoid malignancy).

The study was carried out in Benin City, Edo state. Blood samples collected and analyses were made for full blood count. Ethical clearance was obtained from ministry of health, Edo state ethical committee and oral consent was obtained from the patients before their names were inputted into the data collection form.

\subsection{Sample Collection}

Blood samples were collected using sterile EDTA. This was achieved by tying a tourniquet above a prominent vein, and a sterile swab used to clean the area to reduce the risk of contamination. With a sterile syringe, blood is collected from the vein and immediately put into an EDTA bottle. The blood was mixed gently to avoid coagulation. All samples collected were properly labeled send to haematlogy laboratory of University of Benin teaching hospital for processing within 2 hours of collection.

\subsection{Processing of Samples}

Full blood count was done by Sysmex Automated Hematology Analyzer Kx-21 within two hours of sample collection in EDTA container. This instrument uses electronic low-voltage direct current resistance principle: Cells are sized and counted by detecting and measuring changes in electrical resistance when a particle passes through a small aperture.

\section{Statistical Analysis}

The various laboratory data obtained was analysed using the Statistical Package for Social Sciences (SPSS) version 16. Results were expressed as mean \pm standard deviation (SD) and student's t- test was used for comparison. Differences will be considered significant at an error probability of $\mathrm{P}$ less than 0.05 .

\section{Results}

Table 1: Demographic and Clinical Characteristic of Lymphoid Malignant Patients

\begin{tabular}{|lcc|}
\hline Characteristic & Total of Patients Number & Percentage (\%) \\
\hline No. of patients & 40 & \\
Ages(years) & & 15.0 \\
$25-40$ & 6 & 27.5 \\
$41-55$ & 11 & 52.5 \\
$56-70$ & 21 & 5.0 \\
$71-85$ & 2 & \\
Gender & 19 & 47.5 \\
Male & 21 & 52.5 \\
Female & 13 & 32.5 \\
Lymphoid Malignancy & 12 & 30 \\
Multiple Myeloma & 6 & 15 \\
Hodgkin Lymphoma & 9 & 22.5 \\
Non-Hodgkin Lymphoma & & \\
Chronic Lymphocytic Leukaemia & & \\
& & \\
\hline
\end{tabular}

The general demographic and clinical characteristics of lymphoid malignant patients were detailed in above Tables. The median age of all patients was 56 years (range 25-85 years). There were 19 (47.5\%) males and 21 $(52.5 \%)$ females in the (1:1) ratio. The lymphoid malignant patients observed were: Multiple myeloma $13(32.5 \%)$, Hodgkin Lymphoma 12(30\%), non-hodgkin lymphoma 6(15\%) and Chronic Lymphocytic Leukaemia 9(22.5\%). 
Table 2: Comparison of Haematological Parameters between Noval Lymphoid Malignancy and Control.

\begin{tabular}{|lcccc|}
\hline Parameters & Controls & not Chemotherapy & t-value & p-value \\
\hline Full blood count & & & & \\
Total White blood cells $\left(10^{3} / \mathrm{ul}\right)$ & $5.13 \pm 1.27$ & $42.12 \pm 32.06$ & 5.2 & .000 \\
Red blood cells(10\%/ul) & $4.89 \pm 0.57$ & $3.12 \pm 1.156$ & 5.8 & .000 \\
Haemoglobin (g/dl) & $13.55 \pm 2.16$ & $8.4 \pm 2.28$ & 9.68 & .000 \\
Haematocrit value(\%) & $41.2 \pm 5.45$ & $24.97 \pm 7.43$ & 9.137 & .000 \\
Platelets counts(103/ul) & $239.85 \pm 52.27$ & $468.65 \pm 411.64$ & 2.41 & .026 \\
Differentials & & & & \\
Lymphocytes(\%) & $41.14 \pm 10.1$ & $56.06 \pm 23.29$ & 3.16 & .005 \\
Monocytes(\%) & $12.59 \pm 3.79$ & $19.16 \pm 27.994$ & 1.034 & .314 \\
Granulocytes(\%) & $46.27 \pm 25.12$ & $44.76 \pm 25.12$ & .221 & .827 \\
Red cells index & & & & .632 \\
Mean Cell Volume (fl) & $84.48 \pm 11.68$ & $82.01 \pm 8.62$ & .047 & .535 \\
Mean cell Haemoglobin(pg) & $27.72 \pm 4.31$ & $27.79 \pm 3.93$ & & .963 \\
Mean Cell Haemoglobin & & & 3.898 & 0.073 \\
Concentration(g/dl) & $32.70 \pm 1.68$ & $33.77 \pm 1.96$ & & \\
\hline
\end{tabular}

This table showed the comparison of haematological parameters between novel lymphoid malignant patients and controls; WBC, lymphocytes and platelet count increase significantly $(\mathrm{P}<0.05)$ while RBC, HGB, HCT decrease significantly $(\mathrm{P}<0.05)$ when compared with control. However, MCV, MCH, MCHC, monocytes and granulocytes were not significant $(\mathrm{P}>0.05)$.

Table 3: Comparison of Haematological Parameters between Lymphoid Malignancy on Chemotherapy and Control.

\begin{tabular}{|lcccc|}
\hline Parameters & Controls & Chemotherapy & t-value & p-value \\
\hline Full blood count & & & & \\
Total White blood cells $\left(10^{3} / \mathrm{ul}\right)$ & $5.13 \pm 1.27$ & $6.26 \pm 3.45$ & 1.221 & 0.237 \\
Red blood cells(10\%/ul) & $4.89 \pm 0.57$ & $3.92 \pm 0.81$ & 4.326 & 0.000 \\
Haemoglobin (g/dl) & $13.55 \pm 2.16$ & $10.60 \pm 2.09$ & 4.469 & 0.000 \\
Haematocrit value(\%) & $41.20 \pm 5.45$ & $32.94 \pm 5.43$ & 5.447 & 0.000 \\
Platelets counts(10\%/ul) & $239.85 \pm 52.27$ & $267.850 \pm 125.36$ & 0.871 & 0.395 \\
Differentials & & & & 0.667 \\
Lymphocytes(\%) & $41.14 \pm 10.09$ & $44.12 \pm 16.45$ & 1.205 & 0.243 \\
Monocytes(\%) & $12.59 \pm 3.79$ & $11.36 \pm 3.45$ & 0.414 & 0.684 \\
Granulocytes(\%) & $46.27 \pm 11.35$ & $44.53 \pm 15.08$ & & 0.861 \\
Red cells index & $84.48 \pm 11.68$ & $85.08 \pm 11.15$ & 0,177 & 0.711 \\
Mean Cell Volume (fl) & $27.72 \pm 4.31$ & $27.23 \pm 3.87$ & 0.376 & 0.544 \\
Mean cell Haemoglobin(pg) & $32.7 \pm 1.68$ & $32.11 \pm 3.29$ & 0.617 & \\
Mean Cell Haemoglobin & & & & \\
Concentration(g/dl) & & & & \\
& & & & \\
\hline
\end{tabular}

This table indicate the comparison of haematological parameters between lymphoid malignant patients on chemotherapy and controls, RBC, HGB, HCT decrease significantly when compared with control $(\mathrm{P}<0.05)$ while WBC, lymphocytes, platelet, $\mathrm{MCV}, \mathrm{MCH}, \mathrm{MCHC}$, monocytes and granulocytes were not significant $(\mathrm{P}>0.05)$. 
Table 4: Comparison of Haematological Parameters between Novel Lymphoid Malignancy And Lymphoid Malignancy on Chemotherapy.

\begin{tabular}{|lcccc|}
\hline Parameters & Chemotherapy & Not Chemotherapy & t-value & p-value \\
\hline Full blood count & & & & \\
Total White blood cells $\left(10^{3} / \mathrm{ul}\right)$ & $6.26 \pm 3.45$ & $42.13 \pm 32.06$ & 4.916 & 0.000 \\
Red blood cells(10\%/ul) & $3.92 \pm 0.81$ & $3.12 \pm 1.16$ & 2.434 & 0.025 \\
Haemoglobin $(\mathrm{g} / \mathrm{dl})$ & $10.60 \pm 2.10$ & $8.44 \pm 2.28$ & 2.832 & 0.011 \\
Haematocrit value(\%) & $32.94 \pm 32.94$ & $24.97 \pm 7.43$ & 3.896 & 0.001 \\
Platelets counts(10 $/ \mathrm{ul})$ & $267.85 \pm 125.36$ & $468.65 \pm 411.64$ & 1.933 & 0.068 \\
Differentials & & & & \\
Lymphocytes(\%) & $44.12 \pm 16.45$ & $56.06 \pm 23.29$ & 1.824 & 0.084 \\
Monocytes(\%) & $11.36 \pm 3.45$ & $19.16 \pm 27.99$ & 1.228 & 0.234 \\
Granulocytes(\%) & $44.53 \pm 15.08$ & $44.76 \pm 25.12$ & 0.035 & 0.973 \\
Red cells index & & & & \\
Mean Cell Volume (fl) & $85.08 \pm 11.15$ & $82.01 \pm 8.616$ & 1.055 & 0.305 \\
Mean cell Haemoglobin(pg) & $27.23 \pm 3.87$ & $27.79 \pm 3.93$ & 0.579 & 0.569 \\
Mean Cell Haemoglobin & & & & \\
Concentration(g/dl) & $32.11 \pm 3.29$ & $33.77 \pm 1.96$ & 2.234 & 0.038 \\
\end{tabular}

This table shows the comparison of haematological parameters between lymphoid malignant patients on chemotherapy and novel lymphoid malignant patients, RBC, HGB, HCT increase significantly when compared with novel lymphoid malignant patients $(\mathrm{P}<0.05)$ while $\mathrm{WBC}$ and $\mathrm{MCHC}$ decrease significantly $(\mathrm{P}<0.05)$. However, lymphocytes, platelet, $\mathrm{MCV}, \mathrm{MCH}$, monocytes and granulocytes were not significant $(\mathrm{P}>0.05)$.

\section{Discussion}

Full blood count as one of the major haematological parameters is very vital test for diagnosis, evaluation, and treatment of lymphoid malignancy. It provides a lot of information related to bone marrow health which represented by number, type and morphology of blood cells.

In table 2 showed the comparison of haematological parameters between novel lymphoid malignant patients and controls, we found $\mathrm{WBC}$, lymphocytes and platelet count increase significantly $(\mathrm{P}<0.05)$ while RBC, HGB, HCT decrease significantly $(\mathrm{P}<0.05)$ when compared with control. However, MCV, MCH, MCHC, monocytes and granulocytes were not significant $(\mathrm{P}>0.05)$.

When lymphoid malignant patient on chemotherapy and novel lymphoid malignant patient are compared in Table 4, it shows RBC, HGB, HCT increased significantly when compared with novel lymphoid malignant patients $(\mathrm{P}<0.05)$ while $\mathrm{WBC}$ and $\mathrm{MCHC}$ decreased significantly $(\mathrm{P}<0.05)$. However, lymphocytes, platelet, $\mathrm{MCV}, \mathrm{MCH}$, monocytes and granulocytes were not significant $(\mathrm{P}>0.05)$.

This is in an agreement with Sendes study in which there was decreasing in HGB, RBC, HCT and significant increase in white blood cells (WBC) of chronic myeloid leukemia in comparison with control group (7). Similar study carried out with breast cancer also showed significantly low RBC and HGB (8).

In Table 2 and Table 4, we observed the total white cells count $(\mathrm{WBC})$ increased significantly $(\mathrm{P}<0.05)$ in novel lymphoid malignant patients compared with control and those in chemotherapy. This increase may be due to the effect of lymphoid malignancy on red bone marrow and lymphatic system in which presence of many abnormal cells lead to decrease of bone marrow production of normal cells and increasing the number of cancerous cell production. This will lead to malfunction of the affected cell of the body (9).

In the same Table 2 and Table 4, we also observed that RBC, HGB, HCT were significantly low $(\mathrm{P}<0.05)$ both novel malignant patients and those on chemotherapy compared with the controls. This may be due to the accumulation of the cancerous cells in lymph node, bone marrow and spleen causing swelling of these organs and repeated hemorrhage causing shortage in red blood cells number and hemoglobin concentration leading to anemia in those patients (9). Furthermore, metastasis that occurred in the red bone marrow sinuses secrete substances which induce osteolysis that destroys precursors of red blood cells and stem cells responsible for blood cells formation and differentiation processes leading to shortage in red blood cells formation $(10,11)$. Anemia also occurred due to chemotherapy side effect in gastrointestinal tract affecting bone marrow which may lead to partial or stop of blood components production (12).

The comparison between lymphoid malignant patient on chemotherapy and controls in table 3 shows RBC, HGB, HCT decrease significantly when compared with control $(\mathrm{P}<0.05)$ while WBC, lymphocytes, platelet, $\mathrm{MCV}, \mathrm{MCH}, \mathrm{MCHC}$, monocytes and granulocytes were not significant $(\mathrm{P}>0.05)$.

This indicate that the chemotherapy had great effect on WBC but must be monitor to avoid low immunity which can expose the patients to infections $(13,12,14)$. 


\section{Conclusion}

In conclusion, it was discovered that novel lymphoid malignant patients were associated with leucocytosis, thrombocytosis and anaemia. It was also discovered that chemotherapy normalized leucocytes, reduce platelet count and improved the haematocrit value. In the light of these findings, haematological parameters are essential diagnosis for effective management of lymphoid malignant patients in hospital and cancer centers. It can also be a monitoring tool on potency of chemotherapy. Future prospective trials evaluating the predictive value of these blood parameters on the chemotherapy regimens may be useful for tailoring the treatment in each case.

We can finally deduce that full blood count is highly clinically important for an effective management of lymphoid malignant patients on chemotherapy.

\section{Conflicts of Interest}

\section{There is no conflict of interest regarding the publication of this paper.}

\section{References}

1. Rodriguez-Abreu, D., Bordoni, A. and Zucca, E.(2007). Epidemiology of Haematological Malignancies. Annal Oncology.18 (1):13-18.

2. Hoffbrand, A.V., Pettit, J.E. and Moss, P.A. (2001). The Genetics of Haematological Malignancies. In Essential Haematology. 4th edition, 145-161.

3. World Health Organization. (2014). World Cancer Report 2014. pp. Chapter 2.4.

4. Dragana, P. (2002). Effect of CMF-chemotherapy on blood coagulation in patients with breast cancer. Archive of Oncology. 10(2):61-66'2002.

5. Ghosh, K. (1987). Advances in treatment of hematological disorders. Indian Journal Hematology Blood Transfusion. 5:87-94.

6. Ali, L.O (2014). Study effect of Breast Cancer on Some Hematological and Biochemical Parameters in Babylon Province, Iraq. 9(3):20-4.

7. Sendes waleed khalid Othman Al-abdallah (2012) Effects of chronic myeloid leukemia on some haematological parameters and indicators during chemotherapy period. Tikrit Journal of Pharmaceutical Sciences 8(2).

8. Swati, S., Neelima, S., Akshay, K. N., Sanjay, S. C., Reetika, S. and Sarvesh, K (2017). Comparative study of hematological parameters along with effect of chemotherapy and radiotherapy in different stages of breast cancer. International Journal of Research in Medical Sciences Shrivastava S et al. Int J Res Med Sci. 5(1):311315.

9. Qazilbash, M.H. and Cortes, J.E. (2005).Chronic myeloid leukemia. In: Abraham, J. ;Gulley, J.L. \& Allegra, C.J.(Eds.). Bethesda Handbook of Clinical Oncology 2nd ed. Lippinccott Williams \&Wilkins.USA.PP:331336.

10. Brock, J and Mulero, V.(2000). Cellular and molecular aspects of iron and immune function. Proc. Nutr. Soc. (59): 537-540.

11. Weinberg, E. (2000). Modulation of intramacrophage iron metabolism during microbial cell invasion. Microbes Infect. 2: 85-89.

12. Crist ,M.W.(2000).Neoplastic diseases \& tumors .In: Behrman, R.E.; Kliegman, R.M. \& Jenson, H.B. Nelson Textbook of pediatrics. 16th ed.W .B. Saunders Company, Philadelphia.

13. Haslett, C., Chilvers, E., Boon, N.A. and Celledge, N.R.(2002). Davidsons principles \& practice of medicine .19th ed .Edinburgh .p:929-938.

14. Trapp, O. M., Beykirch, M. K. and Petrides, P. E. (1998). Anagrelide for Treatment of Patients with Chronic Myelogenous Leukemia and a High Platelete Count Blood Cells. Molecules, and Diseases 24(2) Jan 31: 9 13. 